\title{
Integration of Nutrient Sensing in Fish Hypothalamus
}

\author{
José L. Soengas* \\ Laboratorio de Fisioloxía Animal, Departamento de Bioloxía Funcional e Ciencias da Saúde, Facultade de Bioloxía \\ and Centro de Investigación Mariña, Universidade de Vigo, Vigo, Spain
}

OPEN ACCESS

Edited by:

Lionel Carneiro,

The Ohio State University,

United States

Reviewed by:

Miguel López,

University of Santiago

de Compostela, Spain

Young-Hwan Jo,

Albert Einstein College of Medicine,

United States

*Correspondence:

José L. Soengas

jsoengas@uvigo.es

Specialty section:

This article was submitted to

Neuroenergetics, Nutrition and Brain

Health,

a section of the journal

Frontiers in Neuroscience

Received: 15 January 2021

Accepted: 26 January 2021

Published: 26 February 2021

Citation:

Soengas JL (2021) Integration of Nutrient Sensing in Fish

Hypothalamus.

Front. Neurosci. 15:653928.

doi: 10.3389/fnins.2021.653928
The knowledge regarding hypothalamic integration of metabolic and endocrine signaling resulting in regulation of food intake is scarce in fish. Available studies pointed to a network in which the activation of the nutrient-sensing (glucose, fatty acid, and amino acid) systems would result in AMP-activated protein kinase (AMPK) inhibition and activation of protein kinase B (Akt) and mechanistic target of rapamycin (mTOR). Changes in these signaling pathways would control phosphorylation of transcription factors cAMP response-element binding protein (CREB), forkhead box01 (FoxO1), and brain homeobox transcription factor (BSX) leading to food intake inhibition through changes in the expression of neuropeptide Y (NPY), agouti-related peptide (AgRP), proopio melanocortin (POMC), and cocaine and amphetamine-related transcript (CART). The present mini-review summarizes information on the topic and identifies gaps for future research.

Keywords: fish, food intake regulation, nutrient sensors, transcription factors, hypothalamic integration

\section{INTRODUCTION}

Two neuronal populations in the mammalian hypothalamic arcuate nucleus respond to a rise in the levels of circulating metabolites (fatty acid, glucose, and amino acid) (Blouet and Schwartz, 2010; Morton et al., 2014). They respond with decreased expression of agouti-related peptide (AgRP) and neuropeptide $\mathrm{Y}$ (NPY) or increased expression of cocaine and amphetamine-related transcript (CART) and pro-opio melanocortin (POMC). These two populations inhibit each other and signal to higher-order neurons in other areas producing other neuropeptides, and food intake changes due to all these interactions.

In fish, AgRP/NPY and POMC/CART neurons are present in the ventral part of nucleus lateralis tuberis (NLTv), an analog of arcuate nucleus (Soengas et al., 2018). These neurons connect to other neuronal populations, both in hypothalamic and extra-hypothalamic locations, though their neuropeptide production is mostly unknown (Soengas et al., 2018). The regulation of energy expenditure and food intake relies on detection in vertebrate hypothalamus of changes in nutrient levels through different sensing mechanisms as demonstrated in mammals (Efeyan et al., 2015; Bruce et al., 2017) and fish (Soengas, 2014; Delgado et al., 2017; Soengas et al., 2018). Evidence obtained in rainbow trout (Polakof et al., 2009; Otero-Rodiño et al., 2019b) suggest a relationship between neuropeptide expression and nutrient sensing based on the simultaneous presence in hypothalamic areas of proteins involved in nutrient sensing, such as glucokinase (GCK), and the four neuropeptides. The activation of nutrient sensors enhances the anorexigenic potential (ratio between mRNA abundance of anorexigens and orexigens) through decreased expression of AgRP 
and NPY and increased expression of CART and POMC resulting in a decrease in food intake (Delgado et al., 2017; Soengas et al., 2018).

Studies carried out in rainbow trout (Librán-Pérez et al., 2012, 2013, 2014, 2015; Velasco et al., 2016a, 2020; Roy et al., 2020) demonstrated the presence in hypothalamus of fatty acid sensing mechanisms responsive to changes in the levels of long-chain fatty acids like oleate through carnitine palmitoyl transferase-1, mitocondrial ROS production inhibiting ATP-dependent inward rectified potassium channel $\left(\mathrm{K}^{+}{ }_{A T P}\right)$, specific fatty acid receptors (FFAR), fatty acid translocase, and lipoprotein lipase. Evidence is also available in other species like grass carp (Li et al., 2016; Tian et al., 2017), Senegalese sole (Conde-Sieira et al., 2015), zebrafish (Liu et al., 2017), Chinese perch (Luo et al., 2020), and blunt snout bream (Dai et al., 2018). Mechanisms are similar to those characterized in mammals (Lipina et al., 2014; Magnan et al., 2015) though fish are also sensitive to polyunsaturated fatty acid like $\alpha$-linolenate and medium-chain fatty acid like octanoate. Glucose is also sensed in fish hypothalamus. Evidence obtained suggested the presence in rainbow trout (Polakof et al., 2007a,b, 2008a,b,c) and Japanese flounder (Liu et al., 2019) of the canonical mechanism based on GCK, glucose facilitative transporter 2, and $\mathrm{K}^{+}{ }_{A T P}$. Evidence also supports mechanisms not dependent on GCK like those based on liver X receptor and sweet taste receptor (Otero-Rodiño et al., 2015, 2016, 2017; Balasubramanian et al., 2016). Leucine is the unique branched-chain amino acid (BCAA) whose levels are detected by mammalian hypothalamic amino acid sensing mechanisms (Efeyan et al., 2015; Heeley and Blouet, 2016). In fish, available evidence is restricted to rainbow trout (Comesaña et al., 2018a,b) and Chinese perch (Chen et al., 2021), suggesting the existence of mechanisms based on BCAA metabolism, glutamine metabolism, mechanistic target of rapamycin (mTOR), general control nonderepressible 2 kinase, and taste receptor signaling.

The connection between nutrient-sensing systems and the expression of AgRP/NPY and POMC/CART governing food intake is not clear. In mammals, several transcription factors could be involved (López et al., 2007; Diéguez et al., 2011) including brain homeobox transcription factor (BSX), phosphorylated cAMP response-element binding protein (CREB), and forkhead box01 (FoxO1). Changes in these transcription factors would respond to nutrient-sensing systems through mediation by different signaling pathways (Gao et al., 2013; Morton et al., 2014) including AMP-activated protein kinase (AMPK), mTOR, and protein kinase B (Akt). In the following sections, we will show available knowledge in fish regarding each of these pathways.

\section{SIGNALING PATHWAYS}

\section{AMPK}

As an energy sensor, AMPK detects lowered cell energy statuseliciting mechanisms to restore energy balance (López, 2017). Thus, when levels of nutrients rise, a decrease occur in the levels and phosphorylation status of AMPK in mammalian hypothalamus, as demonstrated for glucose, leucine, and fatty acid (Diéguez et al., 2011; Fromentin et al., 2012; Oh et al., 2016).

In fish, several studies evaluated AMPK in brain (Zeng et al., 2016; Xu et al., 2018; Abernathy et al., 2019; Yang et al., 2019) but only a few addressed its role in the regulation of feed intake. Thus, in rainbow trout fed a lipid-enriched diet, a decrease occurred in phosphorylation status of hypothalamic AMPKa (Librán-Pérez et al., 2015). This is comparable with that observed in the same species (Kamalam et al., 2012) or in Megalobrama amblycephala (Xu et al., 2017) when fed a carbohydrate-enriched diet. Also in rainbow trout, raising levels of nutrients like oleate (Velasco et al., 2016a, 2017b; Blanco et al., 2020), octanoate (Velasco et al., 2017b), glucose (Otero-Rodiño et al., 2017), or $\beta$-hydroxybutyrate (Comesaña et al., 2019) also resulted in a decrease in phosphorylation status of AMPK $\alpha$. The specificity of AMPK $\alpha$ response was supported by the disappearance of responses to oleate in the presence of the AMPKa inhibitor compound C (Velasco et al., 2017b). In contrast to the mammalian model, no changes in phosphorylation status of AMPK $\alpha$ occurred in rainbow trout hypothalamus in response to raised leucine levels (Comesaña et al., 2018a,b, 2020). Changes in AMPK also occurred in liver of fish species under different feeding status including a decrease in refed rainbow trout (Polakof et al., 2011) or an increase in food-deprived zebrafish (Craig and Moon, 2011). A role for hypothalamic AMPKa in food intake control is also supported by the increase observed in hypothalamus of food-deprived rainbow trout (Conde-Sieira et al., 2019). The involvement of AMPK is further supported by the decrease in phosphorylation status of AMPK $\alpha$ observed in rainbow trout hypothalamus under anorectic conditions like treatment with ceramide (Velasco et al., 2016b, 2017a), FFAR agonists (Velasco et al., 2020), or anorectic hormones like CCK (Velasco et al., 2019), GLP-1 (Velasco et al., 2019), or insulin (Blanco et al., 2020). Of the different isoforms of AMPK $\alpha$, it seems that AMPK $\alpha 2$ is involved in feed intake regulation while AMPK $\alpha 1$ appears to modulate peripheral metabolism (Conde-Sieira et al., 2019).

\section{mTOR}

Several studies demonstrate increased mTOR mRNA abundance and phosphorylation status in hypothalamus after a rise in the levels of leucine in mammals (Hu et al., 2016; Pena-Leon et al., 2020). In contrast, the effects of fatty acid or glucose on central mTOR are mostly unknown (André and Cota, 2012). However, the anorectic response induced by leptin treatment increase phosphorylation status of mTOR (Kwon et al., 2016) whereas the orexigenic response induced by ghrelin treatment (André and Cota, 2012) or food deprivation (Ferro Cavalcante et al., 2020) decreased mTOR.

In fish, mTOR was characterized in hypothalamus of several species including rainbow trout (Velasco et al., 2017b; Comesaña et al., 2018a; Blanco et al., 2020) and Japanese sea bass (Liang et al., 2019). In rainbow trout, mTOR levels and phosphorylation status responded with an increase to the presence of nutrients like oleate (Velasco et al., 2017b; Blanco et al., 2020), octanoate (Velasco et al., 2017b), glucose (Blanco et al., 2020), or leucine (Comesaña et al., 2018a,b). The presence of rapamycin blocked 
the response to fatty acids in hypothalamus (Velasco et al., 2017b) supporting the specificity of the response. Additional studies relate mTOR to food intake regulation in fish. Thus, increased mTOR occurred under anorectic conditions like feeding a lipidenriched diet in rainbow trout (Librán-Pérez et al., 2015) and blunt snout bream (Dai et al., 2018) or different treatments in rainbow trout with PYY (Velasco et al., 2018), CCK (Velasco et al., 2019), insulin (Blanco et al., 2020), or ceramide (Velasco et al., 2017a). In other fish species, available information is limited. Thus, in Japanese sea bass, hypothalamic mTOR activation modulates POMC and NPY expression (Liang et al., 2019) whereas in cavefish, CCK treatment increased mTOR levels (Penney and Volkoff, 2014). In liver, mTOR phosphorylation status also changed under different feeding status. mTOR increases after a rise in levels of amino acids (Lansard et al., 2011; Wacyk et al., 2012; Liang et al., 2016; Skiba-Cassy et al., 2016), feeding lipid-enriched diets (Librán-Pérez et al., 2015; Zeng et al., 2016), or refeeding (Lansard et al., 2009; Wade et al., 2014) while a decrease occurred under food deprivation (Craig and Moon, 2011).

\section{Akt}

In mammals, Akt levels and phosphorylation status in hypothalamus increased in response to a rise in the concentration of nutrients such as glucose (Chalmers et al., 2014), leucine (Hu et al., 2016), and $\beta$-hydroxybutyrate (Park et al., 2011). This response also occurred under anorectic situations in which hypothalamic POMC mRNA abundance increase (Kwon et al., 2016).

In fish, several evidence suggests the involvement of Akt in the hypothalamic mechanisms related to food intake control. Treatment with nutrients activates this signal through increased phosphorylation status, as demonstrated in rainbow trout for oleate (Blanco et al., 2020), octanoate (Velasco et al., 2017b), glucose (Otero-Rodiño et al., 2017), and leucine (Comesaña et al., 2018a). This activation also occurred under anorectic conditions such as treatment with ceramide (Velasco et al., 2016b, 2017a), insulin (Blanco et al., 2020), leptin (Gong et al., 2016), or FFAR agonists (Velasco et al., 2020). A comparable increase occurred in brain when fish were fed diets enriched in carbohydrates, as observed in zebrafish (Jörgens et al., 2015) and rainbow trout (Dai et al., 2014; Jin et al., 2014) or by feeding lipidenriched diets as demonstrated in rainbow trout (Librán-Pérez et al., 2015) and blunt snout bream (Dai et al., 2018). The response of Akt to the rise in fatty acid levels disappeared in the presence of Akt inhibitor perifosine (Velasco et al., 2017b). Akt involvement in food intake regulation is also supported by the opposed response (decreased phosphorylation status) elicited by the orexigenic ghrelin treatment (Velasco et al., 2017a). In mammals, the activation of Akt signaling in the hypothalamus also resulted in changes in fatty acid metabolism due to the activation of sterol regulatory element-binding protein 1 (SREBP1) and its target genes ATP citrate synthase (ACLY) and fatty acid synthase (FAS) (Kim et al., 2007). In rainbow trout hypothalamus, enhanced phosphorylation of Akt also occurred in parallel with mRNA abundance of acly, fas, and srebp1 (Velasco et al., 2016b). Finally, besides central action, Akt is involved in peripheral responses to changes in feeding status. Thus, refeeding enhanced Akt phosphorylation in liver of barramundi (Wade et al., 2014) and rainbow trout (Lansard et al., 2009; Seiliez et al., 2011), and in muscle of Senegalese sole (Borges et al., 2014).

\section{TRANSCRIPTION FACTORS}

\section{BSX}

The transcription factor BSX interacts with CREB resulting in a parallel increase in the mRNA abundance of Bsx, Npy, and Agrp in mammalian hypothalamus (Nogueiras et al., 2008; Varela et al., 2011; Lee et al., 2016). Accordingly, Bsx decrease under anorectic conditions such as feeding a high-fat diet (Nogueiras et al., 2008) and increase under orexigenic conditions such as food deprivation (Nogueiras et al., 2008) or ghrelin treatment (Lage et al., 2010).

In fish, evidence regarding BSX role in hypothalamus is limited (Cremona et al., 2004; Schredelseker et al., 2020) with a few studies in rainbow trout related to food intake control. In this species, the exposure to oleate (Conde-Sieira et al., 2018) or glucose (Conde-Sieira et al., 2018; Blanco et al., 2020) reduced food intake in parallel with decreased BSX levels. There is no information available for BSX response in fish hypothalamus to the rise in amino acid levels. Other conditions known to decrease food intake in this species also decreased values for BSX as demonstrated by treatment with CCK (Velasco et al., 2019), GLP1 (Velasco et al., 2019), or FFAR agonists (Velasco et al., 2020). No comparable studies assessed changes in Bsx mRNA expression under conditions of raised nutrient levels, not even in mammals. However, indirect evidence is available such as the effects of the treatment with the anorectic hormone leptin in rat resulting in decreased mRNA levels of $B s x$ in arcuate nucleus (Nogueiras et al., 2008) as well as in whole hypothalamus (Gao et al., 2011) in parallel with decreased food intake and Npy mRNA levels. In addition, situations in which an orexigenic response occurred (such as those elicited by ghrelin treatment or food deprivation) induced a rise in hypothalamic Bsx mRNA abundance (Nogueiras et al., 2008; Lage et al., 2010).

\section{CREB}

cAMP response-element binding protein is another transcription factor hypothesized to be involved in the connection between brain metabolism and neuropeptides expression. Accordingly, in mammals, a decrease in CREB levels induced a decrease in mRNA abundance of Npy and Agrp leading to a decrease in food intake (Belgardt et al., 2009; Blanco de Morentin et al., 2011; Varela et al., 2011). CREB protein abundance decrease when food intake is inhibited enhancing anorexigenic potential through a decrease in mRNA levels of Npy and Agrp (Fukushima et al., 2015; Kwon et al., 2016) while levels increase under orexigenic situations such as ghrelin treatment (Lage et al., 2010) or food deprivation (Ren et al., 2013).

In fish, available information regarding CREB involvement in food intake regulation is restricted to rainbow trout. In this species, CREB phosphorylation status decreased in response to raised levels of oleate (Velasco et al., 2017b; 
Conde-Sieira et al., 2018), octanoate (Velasco et al., 2017b), glucose (Conde-Sieira et al., 2018; Otero-Rodiño et al., 2019a), or leucine (Comesaña et al., 2018a,b). CREB response to fatty acids was abolished by the presence of the CBP-CREB interaction inhibitor (Velasco et al., 2017b). Changes observed in CREB are comparable with those observed under other anorectic situations such as treatment with CCK o GLP-1 (Velasco et al., 2019). Moreover, increased levels of CREB occurred in zebrafish under the orexigenic conditions elicited by food deprivation (Craig and Moon, 2011).

\section{Fox01}

Forkhead box01 is likely involved in the relationship between metabolic changes in hypothalamus and the production of neuropeptides (Gross et al., 2009). Thus, in mammals, situations in which Fox01 increased resulted in an enhancement of Agrp mRNA values while those of Pomc decreased, changes favoring a decrease in food intake (Belgardt et al., 2009; Blanco de Morentin et al., 2011).

In fish, FoxO1 was characterized in brain in rainbow trout (Conde-Sieira et al., 2018) and turbot (Pan et al., 2019). Increased levels of nutrients enhanced its abundance and phosphorylation status as observed in rainbow trout for oleate (Conde-Sieira et al., 2018; Blanco et al., 2020), octanoate (Velasco et al., 2017b), and glucose (Conde-Sieira et al., 2018; Blanco et al., 2020). The specificity of FoxO1 response to raised levels of fatty acid was supported by its lack of response in the presence of the FoxO1 inhibitor AS1842856 (Velasco et al., 2017b). In contrast, FoxO1 does not appear to respond to changes in the levels of leucine (Comesaña et al., 2018a,b, 2020). Other anorectic conditions also resulted in increased FoxO1 in rainbow trout as observed after treatment with CCK (Velasco et al., 2019), GLP-1 (Velasco et al., 2019), insulin (Blanco et al., 2020), ceramide (Velasco et al., 2016b, 2017a), or FFAR agonists (Velasco et al., 2020). Central changes in FoxO1 are comparable with those occurring in peripheral tissues under different feeding status. Thus, in liver of rainbow trout orexigenic conditions like refeeding decreased FoxO1 levels (Dai et al., 2013) whereas in grass carp adipogenesis (a situation comparable with a rise in nutrient levels) increased FoxO1 in adipocytes (Sun et al., 2017). No prior studies in any other vertebrate species addressed the hypothalamic response of Foxo1 to changes in nutrient levels. However, changes observed in fish would be comparable with those observed in mammalian hypothalamus under anorectic conditions like feeding a highfat diet (Yuan et al., 2012) or treatment with insulin or leptin (Diéguez et al., 2011; Kwon et al., 2016). Akt activation is known to induce in mammals the phosphorylation of FoxO1 (Belgardt et al., 2009; Gross et al., 2009), which also result in enhanced CART and POMC expression (Kwon et al., 2016). In fish, a

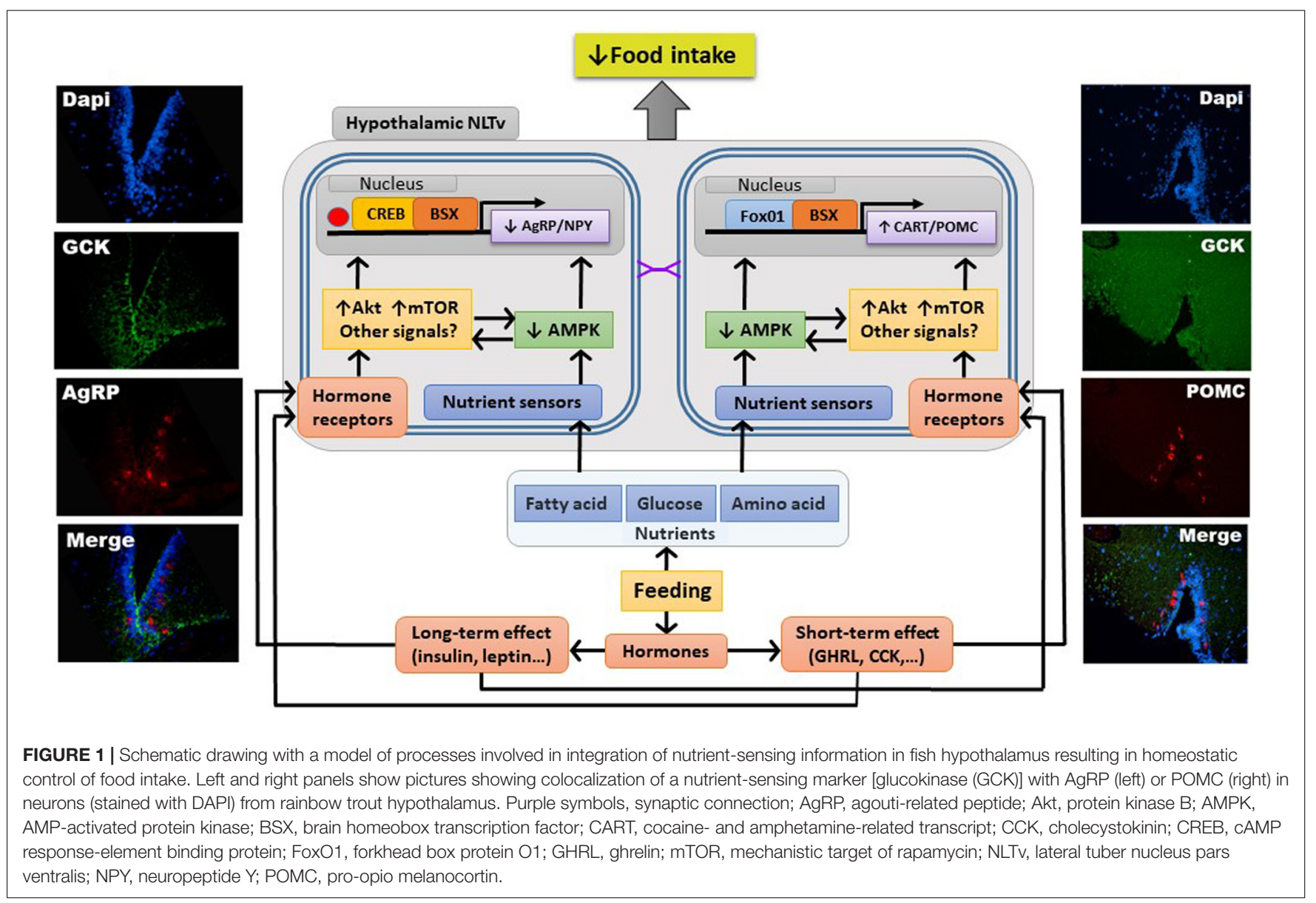


simultaneous rise in Akt and FoxO1 occurred in rainbow trout hypothalamus in response to anorectic treatments like oleate (Blanco et al., 2020), octanoate (Velasco et al., 2017b), or insulin (Blanco et al., 2020) but not leucine (Comesaña et al., 2018a). These results allow me to suggest a relationship between Akt and FoxO1 comparable with that suggested in mammals though restricted to several anorectic conditions.

\section{INTERACTION NUTRIENTS-HORMONES}

AgRP/NPY and CART/POMC neurons involved in the integration of signals from nutrient sensors also have receptors for hormones like leptin, ghrelin, insulin, CCK, or GLP-1, among others (Blouet and Schwartz, 2010; Morton et al., 2014). The binding of these hormones to their receptors in hypothalamic neurons elicits changes in intracellular signals like AMPK and mTOR. Therefore, the final effect on food intake elicited by changes in neuropeptide expression would result from the interaction on signal transduction of both nutrients and hormones. However, this interaction is mostly unknown, with only some evidence available regarding the interactive effects of leptin or ghrelin on fatty acid sensing (López et al., 2007; Blanco de Morentin et al., 2011; Lockie et al., 2019).

In fish, only two studies carried out in rainbow trout demonstrated interactive effects in hypothalamus between nutrient-sensing mechanisms and hormones such as ghrelin and insulin. The presence of oleate counteracted ghrelin effects on AMPK (Velasco et al., 2016a). In the case of insulin (Blanco et al., 2020), its counteractive effects occurred in the presence of glucose for $b s x$ and mtor mRNA abundance as well as in the presence of oleate for Akt phosphorylation status, and foxo1 and creb1 mRNA abundance. No other studies characterized in fish putative interactions in hypothalamus. However, in rainbow trout treatment with different hormones alter nutrient sensing mechanisms in hypothalamus (Conde-Sieira and Soengas, 2017) as demonstrated for glucosensing (leptin, insulin, ghrelin, nesfatin-1, CCK, and GLP-1) and fatty acid sensing (insulin, ghrelin, PYY, and nesfatin-1). Therefore, it is reasonable to

\section{REFERENCES}

Abernathy, O., Kostner, D., Buer, P., Dougherty, M., Schmidtberger, A., Spainhour, R., et al. (2019). Expression of messenger RNA encoding two cellular metabolic regulators, AMP-activated protein kinase (AMPK) and O-GlcNAc transferase (OGT), in channel catfish: their tissue distribution and relationship with changes in food intake. Comp. Biochem. Physiol. A Mol. Integr. Physiol. 235, 12-21. doi: 10.1016/j.cbpa.2019.04.023

André, C., and Cota, D. (2012). Coupling nutrient sensing to metabolic homeostasis: the role of the mammalian target of rapamycin complex 1 pathway. Proc. Nutr. Soc. 71, 502-510. doi: 10.1017/S0029665112000754

Balasubramanian, M. N., Panserat, S., Dupont-Nivet, M., Quillet, E., Montfort, J., Le Cam, A., et al. (2016). Molecular pathways associated with the nutritional programming of plant-based diet acceptance in rainbow trout following an early feeding exposure. BMC Genomics 17:449. doi: 10.1186/s12864-016-2804-1

Belgardt, B. F., Okamura, T., and Brüning, J. C. (2009). Hormone and glucose signalling in POMC and AgRP neurons. J. Physiol. 587(Pt 22), 5305-5314. doi: 10.1113/jphysiol.2009.179192 hypothesize the existence of additional interactions through changes in cellular signaling and transcription factors.

\section{CONCLUSION AND PERSPECTIVES}

The knowledge available in fish about hypothalamic integration of information of metabolic and endocrine nature eliciting changes in expression of neuropeptides ultimately regulating food intake is limited (Delgado et al., 2017; Soengas et al., 2018). Studies in fish suggest the existence of a network similar in some aspects (but not in others) to that of mammals. In this network, the activation of the nutrient-sensing systems would result in the activation of Akt and mTOR as well as in the inhibition of AMPK. Changes in these signals would result in enhanced levels and phosphorylation status of FoxO1 while decreasing those of CREB and BSX. Finally, these changes in transcription factors would ultimately lead to inhibition of food intake inhibition through changes in neuropeptides (AgRP, NPY, POMC, and CART) expression, as observed in fish hypothalamus under anorectic conditions elicited by raised levels of nutrients. However, the precise mechanisms involved and their interaction with hormones still needs evaluation. A summary of available knowledge is shown in Figure 1.

\section{AUTHOR CONTRIBUTIONS}

The author confirms being the sole contributor of this work and has approved it for publication.

\section{FUNDING}

This study was supported by research grants from the Spanish Agencia Estatal de Investigación and European Fund of Regional Development (PID2019-103969RB-C31) and Xunta de Galicia (Consolidación e estructuración de unidades de investigación competitivas do SUG, ED431B 2019/37).

Blanco, A. M., Bertucci, J. I., Soengas, J. L., and Unniappan, S. (2020). In vitro insulin treatment reverses changes elicited by nutrients in cellular metabolic processes that regulate food intake in fish. J. Exp. Biol. 223(Pt 8), jeb213454. doi: $10.1242 /$ jeb. 213454

Blanco de Morentin, P. B., González, C. R., Saha, A. K., Martins, L., Diéguez, C., Vidal-Puig, A., et al. (2011). Hypothalamic AMP-activated protein kinase as a mediator of whole body energy balance. Rev. Endocr. Metab. Disord. 12, 127-140. doi: 10.1007/s11154-011-9165-5

Blouet, C., and Schwartz, G. J. (2010). Hypothalamic nutrient sensing in the control of energy homeostasis. Behav. Brain Res. 209, 1-12. doi: 10.1016/j.bbr.2009.12.024

Borges, P., Valente, L. M. P., Véron, V., Dias, K., Panserat, S., and Médale, F. (2014). High dietary lipid level is associated with persistent hyperglycaemia and downregulation of muscle Akt-mTOR pathway in Senegalese sole (Solea senegalensis). PLoS One 9:e102196. doi: 10.1371/journal.pone.0102196

Bruce, K. D., Zsombok, A., and Eckel, R. H. (2017). Lipid processing in the brain: a key regulator of systemic metabolism. Front. Endocrinol. 8:60. doi: 10.3389/ fendo.2017.00060 
Chalmers, J. A., Jang, J. J., and Belsham, D. D. (2014). Glucose sensing mechanisms in hypothalamic cell models: glucose inhibition of AgRP synthesis and secretion. Mol. Cell. Endocrinol. 382, 262-270. doi: 10.1016/j.mce.2013.10.013

Chen, K., Zhang, Z., Li, J., Xie, S., Shi, L.-J., He, Y.-H., et al. (2021). Different regulation of branched-chain amino acid on food intake by TOR signaling in Chinese perch (Siniperca chuatsi). Aquaculture 530:735792. doi: 10.1016/j. aquaculture.2020.735792

Comesaña, S., Conde-Sieira, M., Velasco, C., Soengas, J. L., and Morais, S. (2020). Oral and pre-absorptive sensing of amino acids relates to hypothalamic control of food intake in rainbow trout. J. Exp. Biol. 223(Pt 17):jeb221721. doi: 10.1242/ jeb. 221721

Comesaña, S., Velasco, C., Ceinos, R. M., López Patiño, M. A., Míguez, J. M., Morais, S., et al. (2018a). Evidence for the presence in rainbow trout brain of amino acid-sensing systems involved in the control of food intake. Am. J. Physiol. Regul. Integr. Comp. Physiol. 314, R201-R215. doi: 10.1152/ajpregu. 00283.2017

Comesaña, S., Velasco, C., Conde-Sieira, M., Míguez, J. M., Soengas, J. L., and Morais, S. (2018b). Feeding stimulation ability and central effects of intraperitoneal treatment of L-leucine, L-valine, and L-proline on amino acid sensing systems in rainbow trout: implication in food intake control. Front. Physiol. 9:1209. doi: 10.3389/fphys.2018.01209

Comesaña, S., Velasco, C., Conde-Sieira, M., Otero-Rodiño, C., Míguez, J. M., and Soengas, J. L. (2019). Central treatment of ketone body in rainbow trout alters liver metabolism without apparently altering the regulation of food intake. Front. Physiol. 10:1206. doi: 10.3389/fphys.2019.01206

Conde-Sieira, M., Bonacic, K., Velasco, C., Valente, L. M. P., Morais, S., and Soengas, J. L. (2015). Hypothalamic fatty acid sensing in Senegalese sole (Solea senegalensis): response to long-chain saturated, monounsaturated, and polyunsaturated (n-3) fatty acids. Am. J. Physiol. Regul. Integr. Comp. Physiol. 309, R1521-R1531. doi: 10.1152/ajpregu.00386.2015

Conde-Sieira, M., Capelli, V., Álvarez-Otero, R., Comesaña, S., Liñares-Pose, L., Velasco, C., et al. (2019). Differential role of hypothalamic AMPK $\alpha$ isoforms in fish: an evolutive perspective. Mol. Neurobiol. 56, 5051-5066. doi: 10.1007/ s12035-018-1434-9

Conde-Sieira, M., Ceinos, R. M., Velasco, C., Comesaña, S., López-Patiño, M. A., Míguez, J. M., et al. (2018). Response of rainbow trout (Oncorhynchus mykiss) hypothalamus to glucose and oleate assessed through transcription factors BSX, ChREBP, CREB, and FoxO1. J. Comp. Physiol. A Neuroethol. Sens. Neural Behav. Physiol. 204, 893-904. doi: 10.1007/s00359-018-1288-7

Conde-Sieira, M., and Soengas, J. L. (2017). Nutrient sensing systems in fish: impact on food intake regulation and energy homeostasis. Front. Neurosci. 10:603. doi: 10.3389/fnins.2016.00603

Craig, P. M., and Moon, T. W. (2011). Fasted zebrafish mimic genetic and physiological responses in mammals: a model for obesity and diabetes? Zebrafish 8, 109-117. doi: 10.1089/zeb.2011.0702

Cremona, M., Colombo, E., Andreazzoli, M., Cossu, G., and Broccoli, V. (2004). Bsx, an evolutionary conserved Brain Specific homeoboX gene expressed in the septum, epiphysis, mammillary bodies and arcuate nucleus. Gene Expr. Patterns 4, 47-51. doi: 10.1016/S1567-133X(03)00151-0

Dai, W., Panserat, S., Mennigen, J. A., Terrier, F., Dias, K., Seiliez, I., et al. (2013). Post-prandial regulation of hepatic glucokinase and lipogenesis requires the activation of TORC1 signaling in rainbow trout (Oncorhynchus mykiss). J. Exp. Biol. 216, 4483-4492. doi: 10.1242/jeb.091157

Dai, W., Panserat, S., Terrier, F., Seiliez, I., and Skiba-Cassy, S. (2014). Acute rapamycin treatment improved glucose tolerance through inhibition of hepatic gluconeogenesis in rainbow trout (Oncorhynchus mykiss). Am. J. Physiol. Regul. Integr. Comp. Physiol. 307, R1231-R1238. doi: 10.1152/ajpregu.00166.2014

Dai, Y.-J., Jiang, G.-Z., Yuan, X.-Y., and Liu, W.-B. (2018). High-fatdiet-induced inflammation depresses the appetite of blunt snout bream (Megalobrama amblycephala) through the transcriptional regulation of leptin/mammalian target of rapamycin. Br. J. Nutr. 120, 1422-1431. doi: 10. 1017/S000711451800288X

Delgado, M. J., Cerdá-Reverter, J. M., and Soengas, J. L. (2017). Hypothalamic integration of metabolic, endocrine, and circadian signals in fish: involvement in the control of food intake. Front. Neurosci. 11:354. doi: 10.3389/fnins.2017. 00354

Diéguez, C., Vazquez, M. J., Romero, A., López, M., and Nogueiras, R. (2011). Hypothalamic control of lipid metabolism: focus on leptin, ghrelin and melanocortins. Neuroendocrinology 94, 1-11. doi: 10.1159/000328122
Efeyan, A., Comb, W. C., and Sabatini, D. M. (2015). Nutrient sensing mechanisms and pathways. Nature 517, 302-310. doi: 10.1038/nature 14190

Ferro Cavalcante, T. C., de farias campina, R. C., Araújo de Souza, J., Alves Marcelino da Silva, A., and Lopes de Sousa, S. (2020). Hypothalamic peptide and nutrient sensors gene expression in the hypothalamus of neonatal rat. Brain Res. Bull. 164, 214-220. doi: 10.1016/j.brainresbull.2020.08.005

Fromentin, G., Darcel, N., Chaumontet, C., Marsset-Baglieri, A., Nadkarni, N., and Tom, D. (2012). Peripheral and central mechanisms involved in the control of food intake by dietary amino acids and proteins. Nutr. Res. Rev. 25, 29-39. doi: 10.1017/S0954422411000175

Fukushima, A., Hagiwara, H., Fujioka, H., Kimura, F., Akema, T., and Funabashi, T. (2015). Sex differences in feeding behavior in rats: the relationship with neuronal activation in the hypothalamus. Front. Neurosci. 9:88. doi: 10.3389/ fnins.2015.00088

Gao, S., Moran, T. H., Lopaschuk, G. D., and Butler, A. A. (2013). Hypothalamic malonyl-CoA and the control of food intake. Physiol. Behav. 122, 17-24. doi: 10.1016/j.physbeh.2013.07.014

Gao, S., Zhu, G., Gao, X., Wu, D., Carrasco, P., Casals, N., et al. (2011). Important roles of brain-specific carnitine palmitoyltransferase and ceramide metabolism in leptin hypothalamic control of feeding. Proc. Natl. Acad. Sci. U.S.A. 108, 9691-9696. doi: 10.1073/pnas.1103267108

Gong, N., Jönsson, E., and Björnsson, B. T. (2016). Acute anorexigenic action of leptin in rainbow trout is mediated by the hypothalamic Pi3k pathway. J. Mol. Endocrinol. 56, 227-238. doi: 10.1530/JME-15-0279

Gross, D. N., Wan, M., and Birnbaum, M. J. (2009). The role of FOXO in the regulation of metabolism. Curr. Diab. Rep. 9, 208-214. doi: 10.1007/s11892009-0034-5

Heeley, N., and Blouet, C. (2016). Central amino acid sensing in the control of feeding behavior. Front. Endocrinol. 7:148. doi: 10.3389/fendo.2016.00148

$\mathrm{Hu}, \mathrm{F} ., \mathrm{Xu}, \mathrm{Y}$. , and Liu, F. (2016). Hypothalamic roles of mTOR complex I: integration of nutrient and hormone signals to regulate energy homeostasis. Am. J. Physiol. Endocrinol. Metab. 310, E994-E1002. doi: 10.1152/ajpendo. 00121.2016

Jin, J., Médale, F., Kamalam, B. S., Aguirre, P., Véron, V., and Panserat, S. (2014). Comparison of glucose and lipid metabolic gene expressions between fat and lean lines of rainbow trout after a glucose load. PLoS One 9:e105548. doi: 10.1371/journal.pone.0105548

Jörgens, K., Stoll, S. J., Pohl, J., Fleming, T. H., Sticht, C., Nawroth, P. P., et al. (2015). High tissue glucose alters intersomitic blood vessels in zebrafish via methylglioxal targeting the VEGF receptor signaling cascade. Diabetes 64, 213-225. doi: 10.2337/db14-0352

Kamalam, B. S., Medale, F., Kaushik, S., Polakof, S., Skiba-Cassy, S., and Panserat, S. (2012). Regulation of metabolism by dietary carbohydrate in two lines of rainbow trout divergently selected for muscle fat content. J. Exp. Biol. 215, 2567-2578. doi: 10.1242/jeb.070581

Kim, E.-K., Kleman, A. K., and Ronnett, G. V. (2007). Fatty acid synthase gene regulation in primary hypothalamic neurons. Neurosci. Lett. 423, 200-204. doi: 10.1016/j.neulet.2007.06.056

Kwon, O., Kim, K. W., and Kim, M.-S. (2016). Leptin signalling pathways in hypothalamic neurons. Cell. Mol. Life Sci. 73, 1457-1477. doi: 10.1007/s00018016-2133-1

Lage, R., Vázquez, M. J., Varela, L., Saha, A. K., Vidal-Puig, A., Nogueiras, R., et al. (2010). Ghrelin effects on neuropeptides in the rat hypothalamus depend on fatty acid metabolism actions on BSX but not on gender. FASEB J. 24, 2670-2679. doi: 10.1096/fj.09-150672

Lansard, M., Panserat, S., Plagnes-Juan, E., Dias, K., Seiliez, I., and Skiba-Cassy, S. (2011). L-Leucine, L-Methionine, and L-Lysine are involved in the regulation of intermediary metabolism-related gene expression in rainbow trout hepatocytes. J. Nutr. 141, 75-80. doi: 10.3945/jn.110.124511

Lansard, M., Panserat, S., Seiliez, I., Polakof, S., Plagnes-Juan, E., Geurden, I., et al. (2009). Hepatic protein kinase B (Akt)-target of rapamycin (TOR)-signalling pathways and intermediary metabolism in rainbow trout (Oncorhynchus mykiss) are not significantly affected by feeding plant-based diets. Br. J. Nutr. 102, 1564-1573. doi: 10.1017/S000711450999095X

Lee, B., Lee, S., Lee, S.-K., and Lee, J. W. (2016). The LIM-homeobox transcription factor Isl1 plays crucial roles in the development of multiple arcuate nucleus neurons. Development 143, 3763-3773. doi: 10.1242/dev.133967

Li, A., Yuan, X., Liang, X. F., Liu, L., Li, J., Li, B., et al. (2016). Adaptations of lipid metabolism and food intake in response to low and high fat diets in 
juvenile grass carp (Ctenopharyngodon idellus). Aquaculture 457, 43-49. doi: 10.1016/j.aquaculture.2016.01.014

Liang, H., Ren, M., Habte-Tsion, H. M., Ge, X., Xie, J., Mi, H., et al. (2016). Dietary arginine affects growth performance, plasma amino acid contents and gene expressions of the TOR signaling pathway in juvenile blunt snout bream, Megalobrama amblycephala. Aquaculture 461, 1-8. doi: 10.1016/j.aquaculture. 2016.04.009

Liang, X., Han, J., Xue, M., Yu, H., Huang, H., Wu, X., et al. (2019). Growth and feed intake regulation responses to anorexia, adaptation and fasting in Japanese seabass, Lateolabrax japonicas when fishmeal is totally replaced by plant protein. Aquaculture 498, 528-538. doi: 10.1016/j.aquaculture.2018.09.010

Librán-Pérez, M., Geurden, I., Dias, K., Corraze, G., Panserat, S., and Soengas, J. L. (2015). Feeding rainbow trout with a lipid-enriched diet: effects on fatty acid sensing, regulation of food intake and cellular signaling pathways. J. Exp. Biol. 218, 2610-2619. doi: 10.1242/jeb.123802

Librán-Pérez, M., López-Patiño, M. A., Míguez, J. M., and Soengas, J. L. (2013). Oleic acid and octanoic acid sensing capacity in rainbow trout Oncorhynchus mykiss is direct in hypothalamus and Brockmann bodies. PLoS One 8:e59507. doi: 10.1371/journal.pone.0059507

Librán-Pérez, M., Otero-Rodiño, C., López-Patiño, M. A., Míguez, J. M., and Soengas, J. L. (2014). Central administration of oleate or octanoate activates hypothalamic fatty acid sensing and inhibits food intake in rainbow trout. Physiol. Behav. 129, 272-279. doi: 10.1016/j.physbeh.2014.02.061

Librán-Pérez, M., Polakof, S., López-Patiño, M. A., Míguez, J. M., and Soengas, J. L. (2012). Evidence of a metabolic fatty-acid sensing system in the hypothalamus and Brockmann bodies of rainbow trout: implications in food intake regulation. Am. J. Physiol. Regul. Integr. Comp. Physiol. 302, R1340-R1350. doi: 10.1152/ ajpregu.00070.2012

Lipina, C., Irving, A. J., and Hundal, H. S. (2014). Mitochondria: a possible nexus for the regulation of energy homeostasis by the endocannabinoid system? Am. J. Physiol. Endocrinol. Metab. 307, E1-E13. doi: 10.1152/ajpendo.00100.2014

Liu, D., Deng, K., Sampath, W. W. H. A., Gu, Z., Pan, M., Zhang, Y., et al. (2019). Responses of glucosensing system to glucose in Japanese flounder Paralichthys olivaceus fed diets with different carbohydrate content. Comp. Biochem. Physiol. B Biochem. Mol. Biol. 232, 72-78. doi: 10.1016/j.cbpb.2019.03.001

Liu, H., Xu, Y., Wang, Y., Zhong, S., Wang, M., Lin, P., et al. (2017). Cd36 is a candidate lipid sensor involved in the sensory detection of fatty acid in zebrafish. Physiol. Behav. 182, 34-39. doi: 10.1016/j.physbeh.2017.09.015

Lockie, S. H., Stark, R., Mequinion, M., Ch'ng, S., Kong, D., Spanswick, D. C., et al. (2019). Glucose availability predicts the feeding response to ghrelin in male mice, an effect dependent on AMPK in AgRP neurons. Endocrinology 159, 3605-3614. doi: 10.1210/en.2018-00536

López, M. (2017). EJE PRIZE 2017: hypothalamic AMPK: a golden target against obesity? Eur. J. Endocrinol. 176, R235-R246. doi: 10.1530/EJE-16-0927

López, M., Lelliott, C. J., and Vidal-Puig, A. (2007). Hypothalamic fatty acid metabolism: a housekeeping pathway that regulates food intake. BioEssays 29, 248-261. doi: 10.1002/bies.20539

Luo, H., Liang, X.-F., Li, J., Zhang, Y., Xiao, Q., Peng, B., et al. (2020). Effect of longchain saturated and unsaturated fatty acids on hypothalamic fatty acid sensing in Chinese perch (Siniperca chuatsi). Comp. Biochem. Physiol. B Biochem. Mol. Biol. 241:110395. doi: 10.1016/j.cbpb.2019.110395

Magnan, C., Levin, B. E., and Luquet, S. (2015). Brain lipid sensing and the neural control of energy balance. Mol. Cell Endocrinol. 418(Pt 1), 3-8. doi: 10.1016/j. mce.2015.09.019

Morton, G. J., Meek, T. H., and Schwartz, M. W. (2014). Neurobiology of food intake in health and disease. Nat. Rev. Neurosci. 15, 367-378. doi: 10.1038/ nrn3745

Nogueiras, R., López, M., Lage, R., Perez-Tilve, D., Pfluger, P., Mendieta-Zerón, H., et al. (2008). Bsx, a novel hypothalamic factor linking feeding with locomotor activity, is regulated by energy availability. Endocrinology 149, 3009-3015. doi: 10.1210/en.2007-1684

Oh, Y. T., Oh, H. H., Nguyen, A.-K., Choi, C. S., and Youn, J. H. (2016). Circulating free fatty acids inhibit food intake in an oleate-specific manner in rats. Physiol. Behav. 167, 194-201. doi: 10.1016/j.physbeh.2016.09.015

Otero-Rodiño, C., Conde-Sieira, M., Comesaña, S., Álvarez-Otero, R., LópezPatiño, M. A., Míguez, J. M., et al. (2019a). $\mathrm{Na}^{+} / \mathrm{K}^{+}$-ATPase is involved in the regulation of food intake in rainbow trout but apparently not through brain glucosensing mechanisms. Physiol. Behav. 209:112617. doi: 10.1016/j.physbeh. 2019.112617

Otero-Rodiño, C., Librán-Pérez, M., Velasco, C., López-Patiño, M. A., Míguez, J. M., and Soengas, J. L. (2015). Evidence for the presence of glucosensor mechanisms not dependent on glucokinase in hypothalamus and hindbrain of rainbow trout (Oncorhynchus mykiss). PLoS One 10:e0128603. doi: 10.1371/ journal.pone. 0128603

Otero-Rodiño, C., Rocha, A., Sánchez, E., Álvarez-Otero, R., Soengas, J. L., and Cerdá-Reverter, J. M. (2019b). Sensing glucose in the central melanocortin circuits of rainbow trout: a morphological study. Front. Endocrinol. 10:254. doi: 10.3389/fendo.2019.00254

Otero-Rodiño, C., Velasco, C., Álvarez-Otero, R., López Patiño, M. A., Míguez, J. M., and Soengas, J. L. (2017). Changes in the levels and phosphorylation status of Akt, AMPK, CREB and FoxOl in hypothalamus of rainbow trout under conditions of enhanced glucosensing activity. J. Exp. Biol. 220, 4410-4417. doi: 10.1242/jeb.165159

Otero-Rodiño, C., Velasco, C., Álvarez-Otero, R., López-Patiño, M. A., Míguez, J. M., and Soengas, J. L. (2016). In vitro evidence supports the presence of glucokinase-independent glucosensing mechanisms in hypothalamus and hindbrain of rainbow trout. J. Exp. Biol. 219, 1750-1759. doi: 10.1242/jeb. 137737

Pan, M., Zhang, Y., Deng, K., Liu, G., Gu, Z., Liu, J., et al. (2019). Forkhead box 01 in turbot Scophthalmus maximus: molecular characterization, gene structure, tissue distribution and the role in glucose metabolism. Gene 708, 49-56. doi: 10.1016/j.gene.2019.03.065

Park, S., Kim, D. S., and Daily, J. W. (2011). Central infusion of ketone bodies modulates body weight and hepatic insulin sensititivy by modifying hypothalamic leptin and insulin signaling pathways in type 2 diabetic rats. Brain Res. 1401, 95-103. doi: 10.1016/j.brainres.2011.05.040

Pena-Leon, V., Perez-Lois, R., and Seoane, L. M. (2020). mTOR pathway is involved in energy homeostasis regulation as a part of the gut-brain axis. Int. J. Mol. Sci. 21:5715. doi: 10.3390/ijms 21165715

Penney, C. C., and Volkoff, H. (2014). Peripheral injections of cholecystokinin, apelin, ghrelin and orexin in cavefish (Astyanax fasciatus mexicanus): effects on feeding and on the brain expression levels of tyrosine hydroxylase, mechanistic target of rapamycin and appetite-related hormones. Gen. Comp. Endocrinol. 196, 34-40. doi: 10.1016/j.ygcen.2013.11.015

Polakof, S., Míguez, J. M., Moon, T. W., and Soengas, J. L. (2007a). Evidence for the presence of a glucosensor in hypothalamus, hindbrain, and Brockmann bodies of rainbow trout. Am. J. Physiol. Regul. Integr. Comp. Physiol. 292, R1657-R1666. doi: 10.1152/ajpregu.00525.2006

Polakof, S., Míguez, J. M., and Soengas, J. L. (2007b). In vitro evidences for glucosensing capacity and mechanisms in hypothalamus, hindbrain, and Brockmann bodies of rainbow trout. Am. J. Physiol. Regul. Integr. Comp. Physiol. 293, R1410-R1420. doi: 10.1152/ajpregu.00283.2007

Polakof, S., Míguez, J. M., and Soengas, J. L. (2008a). Changes in food intake and glucosensing function of hypothalamus and hindbrain in rainbow trout subjected to hyperglycemic or hypoglycemic conditions. J. Comp. Physiol. A Neuroethol. Sens. Neural Behav. Physiol. 194, 829-839. doi: 10.1007/s00359008-0354-y

Polakof, S., Míguez, J. M., and Soengas, J. L. (2008b). Dietary carbohydrates induce changes in glucosensing capacity and food intake in rainbow trout. Am. J. Physiol. Regul. Integr. Comp. Physiol. 295, R478-R489. doi: 10.1152/ajpregu. 00176.2008

Polakof, S., Panserat, S., Craig, P. M., Martyres, D. J., Plagnes-Juan, E., Savari, S., et al. (2011). The metabolic consequences of hepatic AMP-kinase phosphorylation in rainbow trout. PLoS One 6:e20228. doi: 10.1371/journal. pone.0020228

Polakof, S., Panserat, S., Plagnes-Juan, E., and Soengas, J. L. (2008c). Altered dietary carbohydrates significantly affect gene expression of the major glucosensing components in Brockmannn bodies and hypothalamus of rainbow trout. Am. J. Physiol. Regul. Integr. Comp. Physiol. 295, R1077-R1088. doi: 10.1152/ajpregu. 90476.2008

Polakof, S., Rodríguez-Alonso, M., and Soengas, J. L. (2009). Immunohistochemical localization of glucokinase in rainbow trout brain. Comp. Biochem. Physiol. A Mol. Integr. Physiol. 153, 352-358. doi: 10.1016/j.cbpa.2009.03.015 
Ren, X., Lufty, K., Mangubat, M., Ferrini, M. G., Lee, M. L., Liu, Y., et al. (2013). Alterations in phosphorylated CREB expression in different brain regions following short- and long-term morphine exposure: relationship to food intake. J. Obes. 2013:764742. doi: 10.1155/2013/764742

Roy, J., Larroquet, L., Surget, A., Lanuque, A., Sandres, F., Terrier, F., et al. (2020). Impact on cerebral function in rainbow trout fed with plant based omega-3 long chain polyunsaturated fatty acids enriched with DHA and EPA. Fish Shellfish Immunol. 103, 409-420. doi: 10.1016/j.fsi.2020.05.044

Schredelseker, T., Veit, F., Dorsky, R. I., and Driever, W. (2020). Bsx is essential for differentiation of multiple neuromodulatory cell populations in the secondary prosencephalon. Front. Neurosci. 14:525. doi: 10.3389/fnins.2020.00525

Seiliez, I., Panserat, S., Lansard, M., Polakof, S., Plagnes-Juan, E., Surget, A., et al. (2011). Dietary carbohydrate-to-protein ratio affects TOR signaling and metabolism-related gene expression in the liver and muscle of rainbow trout after a single meal. Am. J. Physiol. Reg. Integr. Comp. Physiol. 300, R733-R743. doi: 10.1152/ajpregu.00579.2010

Skiba-Cassy, S., Geurden, I., Panserat, S., and Seiliez, I. (2016). Dietary methionine imbalance alters the transcriptional regulation of genes involved in glucose, lipid and amino acid metabolismin the liver of rainbow trout (Oncorhynchus mykiss). Aquaculture 454, 56-65. doi: 10.1016/j.aquaculture.2015.12.015

Soengas, J. L. (2014). Contribution of glucose- and fatty acid sensing systems to the regulation of food intake in fish. A review. Gen. Comp. Endocrinol. 205, 36-48. doi: 10.1016/j.ygcen.2014.01.015

Soengas, J. L., Cerdá-Reverter, J. M., and Delgado, M. J. (2018). Central regulation of food intake in fish: an evolutionary perspective. J. Mol. Endocrinol. 60, R171-R199. doi: 10.1530/JME-17-0320

Sun, J., Xiao, P., Chang, Z. G., Ji, H., Du, Z. Y., and Chen, L. Q. (2017). Forkhead box 01 in grass carp Ctenopharyngodon idella: molecular characterization, gene structure, tissue distribution and mRNA expression in insulin-inhibited adipocyte lipolysis. Comp. Biochem. Physiol. A Mol. Integr. Physiol. 204, 76-84. doi: 10.1016/j.cbpa.2016.11.011

Tian, J., Liu, W., Gao, W., Wu, F., Yu, L., Lu, X., et al. (2017). Molecular cloning and gene/protein expression of FAT/CD36 from grass carp (Ctenopharyngodon idella) and the regulation of its expression by dietary energy. Fish Physiol. Biochem. 43, 875-888. doi: 10.1007/s10695-017-0342-7

Varela, L., Vázquez, M. J., Cordido, F., Nogueiras, R., Vidal-Puig, A., Diéguez, C., et al. (2011). Ghrelin and lipid metabolism: key partners in energy balance. J. Mol. Endocrinol. 46, R43-R63. doi: 10.1677/JME-10-0068

Velasco, C., Blanco, A. M., Unniappan, S., and Soengas, J. L. (2018). The anorectic effect of central PYY1-36 treatment in rainbow trout (Oncorhynchus mykiss) is associated with changes in mRNAs encoding neuropeptides and parameters related to fatty acid sensing and metabolism. Gen. Comp. Endocrinol. 267, 137-145. doi: 10.1016/j.ygcen.2018.06.015

Velasco, C., Comesaña, S., Conde-Sieira, M., Míguez, J. M., and Soengas, J. L. (2019). Effects of CCK- 8 and GLP-1 on fatty acid sensing and food intake regulation in trout. J. Mol. Endocrinol. 62, 101-116. doi: 10.1530/JME-18-0212

Velasco, C., Conde-Sieira, M., Comesaña, S., Chivite, M., Díaz-Rúa, A., Míguez, J. M., et al. (2020). The long-chain fatty acid receptors FFA1 and FFA4 are involved in food intake regulation in fish brain. J. Exp. Biol. 223, jeb227330. doi: $10.1242 /$ jeb. 227330

Velasco, C., Librán-Pérez, M., Otero-Rodiño, C., López-Patiño, M. A., Míguez, J. M., Cerdá-Reverter, J. M., et al. (2016a). Ghrelin modulates hypothalamic fatty acid-sensing and control of food intake in rainbow trout. J. Endocrinol. 228, 25-37. doi: 10.1530/JOE-15-0391
Velasco, C., Librán-Pérez, M., Otero-Rodiño, C., López-Patiño, M. A., Míguez, J. M., and Soengas, J. L. (2016b). Ceramides are involved in regulation of food intake in rainbow trout (Oncorhynchus mykiss). Am. J. Physiol. Regul. Integr. Comp. Physiol. 311, R658-R668. doi: 10.1152/ajpregu.00201.2016

Velasco, C., Moreiras, G., Conde-Sieira, M., Leao, J. M., Míguez, J. M., and Soengas, J. L. (2017a). Ceramide counteracts the effects of ghrelin on the metabolic control of food intake in rainbow trout. J. Exp. Biol. 220(Pt 14), 2563-2576. doi: 10.1242/jeb.159871

Velasco, C., Otero-Rodiño, C., Comesaña, S., Míguez, J. M., and Soengas, J. L. (2017b). Hypothalamic mechanisms linking fatty acid sensing and food intake regulation in rainbow trout. J. Mol. Endocrinol. 59, 377-390. doi: 10.1530/JME17-0148

Wacyk, J., Powell, M., Rodnick, K., Overturf, K., Hill, R., and Hardy, R. (2012). Dietary protein source significantly alters growth performance, plasma variables and hepatic gene expression in rainbow trout (Oncorhynchus mykiss) fed amino acid balanced diets. Aquaculture 356-357, 223-234. doi: 10.1016/j.aquaculture. 2012.05.013

Wade, N. M., Skiba-Cassy, S., Dias, K., and Glencross, B. D. (2014). Postprandial molecular responses in the liver of the barramundi, Lates calcarifer. Fish Physiol. Biochem. 40, 427-443. doi: 10.1007/s10695-013-9854-y

Xu, C., Li, X.-F., Shi, H.-J., Liu, J., Zhang, L., and Liu, W.-B. (2018). AMP-activated protein kinase $\alpha 1$ in Megalobrama amblycephala: molecular charcaterization and the transcriptional modulation by nutrient restriction and glucose and insulin loadings. Gen. Comp. Endocrinol. 267, 66-75. doi: 10.1016/j.ygcen.2018. 05.030

Xu, C., Liu, W. B., Zhang, D. D., Wang, K. Z., Xia, S. L., and Li, X. F. (2017). Molecular characterization of AMP-activated protein kinase $\alpha 2$ from herbivorous fish Megalobrama amblycephala and responsiveness to glucose loading and dietary carbohydrate levels. Comp. Biochem. Physiol. A Mol Integr Physiol. 208, 24-34. doi: 10.1016/j.cbpa.2017.03.008

Yang, S., Wu, H., He, K., Yan, T., Zhou, J., Zhao, L. L., et al. (2019). Response of AMP-activated protein kinase and lactate metabolism of largemouth bass (Micropterus salmoides) under acute hypoxic stress. Sci. Total Env. 666, 10711079. doi: 10.1016/j.scitotenv.2019.02.236

Yuan, M., Pino, E., Wu, L., Kacergis, M., and Soukas, A. A. (2012). Identification of Akt-independent regulation of hepatic lipogenesis by mammalian target of rapamycin (mTOR) complex 2. J. Biol. Chem. 287, 29579-29588. doi: 10.1074/ jbc.M112.386854

Zeng, L., Liu, B., Wu, C.-W., Lei, J.-L., Xu, M.-Y., Zhu, A.-Y., et al. (2016). Molecular characterization and expression analysis of AMPK $\alpha$ subunit isoform genes from Scophthalmus maximus responding to salinity stress. Fish Physiol. Biochem. 42, 1595-1607. doi: 10.1007/s10695-0160243-1

Conflict of Interest: The author declares that the research was conducted in the absence of any commercial or financial relationships that could be construed as a potential conflict of interest.

Copyright (c) 2021 Soengas. This is an open-access article distributed under the terms of the Creative Commons Attribution License (CC BY). The use, distribution or reproduction in other forums is permitted, provided the original author(s) and the copyright owner(s) are credited and that the original publication in this journal is cited, in accordance with accepted academic practice. No use, distribution or reproduction is permitted which does not comply with these terms. 